\title{
Cerrahi Hemşirelerin Basınç Yaralanması, Risk Faktörleri ve Önlenmeye İlişsin Bilgilerin İncelenmesi
}

\section{Examination of Surgical Nurses' Pressure Ulcer, Risk Factors and Knowledge Related to Prevention}

iD Akile Aydoğmuş Ünlü ${ }^{1}$, iD Işı1l Işık Andsoy²

${ }^{1}$ Karabük Üniversitesi Eğitim ve Araştırma Hastanesi.

${ }^{2}$ Karabük Üniversitesi Sağlık Bilimleri Fakültesi.

\section{$\ddot{O} z$}

Amaç: Çalışma cerrahi hemşirelerinin basınç yaralanması, risk faktörleri ve önlemeye ilişkin bilgilerinin değerlendirilmesi amacıyla tanımlayıcı olarak yapıldı.

Gereç ve Yöntem: Çalıșmanın evrenini Karabük ilindeki üniversite, devlet ve özel hastanelerin ameliyathane, cerrahi klinikler ve cerrahi yoğun bakımında çalışan 400 hemşire oluşturdu. Tam sayım örnekleme yöntemi ile çalışmanın yapılacă̆ tarih aralığında izinli veya raporlu olmayan, katılıma istekli ve onam veren 245 cerrahi hemşiresi çalışma kapsamına alındı. Veriler, kişisel bilgi formu ve 'Modifiye Pieper Basınç Yarası Bilgi Testi' ile toplandı. Verilerin değerlendirilmesinde ortalama, standart sapma, Minumum Maksimum, Ortanca ve IQR değerleri, arşılaştırmalarda Mann Whitney U testi, Kruskal Wallis Varyans analizi kullanıldı.

Bulgular: Çalışmada cerrahi hemşirelerin en yüksek oranda doğru yanıt verdikleri konuların sırasıyla yara tanımı, evrelendirilmesi, önleme ve risk olduğu belirlendi. Yoğun bakımda çalışan hemşirelerin önleme ve risk, yara tanımına yönelik aldıkları puanların cerrahi kliniklerde çalışan hemşirelere göre anlamlı düzeyde yüksek ( $\mathrm{p}=0.007)$, basınç yaralanması ile sık karşılaşma, ölçek kullanma, hizmetiçi eğitim alma, basınç yaralanmasına yönelik makale okuma ve internetten araştırma yapma ile hemşirelerin doğru yanıt puan ortalamaları arasında istatistiksel olarak anlamlı fark olduğu görüldü $(\mathrm{p}<0.001)$.

Sonuç: Bu sonuçlar doğrultusunda; cerrahi klinikler ile ameliyathanelerde çalı̧̧an hemşirelere basınç yarası, önleme ve risk değerlendirmeye yönelik hizmet içi eğitim planlama, bilimsel toplantıya katılma ve araştırma yapmaya teşvik etme önerilebilir.

Anahtar Kelimeler: Cerrahi Hemşiresi, Basınç Yarası, Bilgi

\section{Abstract}

Objective: This descriptive study was conducted in order to evaluate the knowledge of surgical nurses about pressure ulcer, risk factors and prevention.

Material and Methods: The universe of the study comrises 400 nurses working in intensive care, operating room and surgical clinics of a university, state and private hospital in Karabük province. 245 surgical nurses who were not on leave or reported, willing to participate in the study and who gave consent were included in the study during the period of the study by the complete counting sampling method. As the data collection for personal information form, Modified Pieper Pressure Ulcer Knowledge Test was used. Frequency and percentage, mean, median and IQR values, Mann-Whitney U test, Kruskal-Wallis were used to evaluate the data.

Results: In this study, the topics for which surgical nurses responded most accurately were pressure ulcer description, staging, prevention and risk assessment, respectively. The prevention and risk, ulcer definition scores of the nurses working in intensive care unit were significantly higher than the nurses working in surgical clinics $(\mathrm{p}=0.007)$, and there was a statistically significant relationship between the frequent exposure with pressure injury, using scales, participating in-service training, reading articles on pressure ulcers and doing research on the internet, and nurses' correct response scores ( $<<0.001)$.

Conclusion: In line with these results, nurses working in surgical clinics and operating rooms may be advised to plan in-service training for pressure ulcer, prevention and risk assessment, to participate in scientific meetings and to encourage them to conduct research.

Keywords: Surgical Nurse, Pressure Ulcer, Knowledge

Yazışma Adresi: Iş̧1 Işık Andsoy, Karabük Üniversitesi Sağlık Bilimleri Fakültesi.

E-Posta: isilandsoy@gmail.com

Alınma Tarihi: 13.02.2020 / Kabul Tarihi: 01.07.2020 / Yayımlanma Tarihi: 15.06.2021

Cerrahi hemşire ve basınç yaralanması - Ünlü ve Andsoy. 


\section{Giriş}

Sağlık bakım hizmetleri sunumundaki gelişme ve yeniliklere karşın, birey ve kurum açısından önemli bir sorun olan basınç yaralanmaları, cilt ve cilt altı dokuların uzun süre basınç altında kalmasına bağlı gelişmektedir (1). Basınç yaralanmaları hastaların yaşam kalitesini olumsuz etkilemekte, hastanede kalış süresini uzatmakta, bakteriyel enfeksiyon, sepsis ve septik şok gibi komplikasyonlara neden olmakta, mortalite ve morbidite riski ile tedavi maliyetlerini de artırmaktadır (2,3). Bu yaralanmalar hastanın bağımsızlığını kaybetme, sosyal izolasyon gibi psikolojik sorunlara yol açmaktadır $(4,5)$. Diğer yandan, basınç yaralanması varlığı hastaların bakım ve tedavisinde doğrudan yer alan hemşirelerin iş yükünü arttırmakta, bakımın kalitesini azaltmakta $(2,6)$, dolayısıyla hemşirelerin istenilen bakım sonucuna ulaşmasını engellemektedir $(7,8)$.

Sağlık Araştırma ve Kalite Ajans1, ABD'de basınç yaralanması nedeniyle yılda yaklaşık 60000 hastanın öldüğünü bildirilmiştir (9). Basınç yaralanmaları sıklıkla yoğun bakım, uzun yatış gerektiren diğer klinikler, ameliyathane ve cerrahi kliniklerde sıklıkla karşılaşılan istenmeyen bir durumdur. Farklı ülkelerde yapılan çalışmalarda basınç yaralanması insidans oranlarının kliniklere göre değişiklik gösterdiği ve \%14 ila \%27,9 (10-12), ameliyat sırasında ise bu yaralanma oranlarının \%4,7-\%66 arasında değiştiği (13) bulunmuştur. Ülkemizde de yoğun bakım klinikleri için \%35,3 (14), cerrahi girişim geçiren hastalar için \%3,5-\%29,5 (15), cerrahi yoğun bakım hastaları için ise yaklaşık \%20,5 (16) olduğu belirtilmektedir.

Basınç yaralanmaları cerrahi hastası için ciddi bir sağlık sorunudur ve hastaların basınç yaralanması gelişimi risk faktörleri açısından çok iyi değerlendirilmesi gerekmektedir (17). Cerrahi girişim uygulanan hastalarda hareketsizlik, uzun süren ve karmaşı cerrahi prosedürler, bilinç düzeyindeki değişiklikler, ileri yaşta olma, mevcut hastalığına eşlik eden hastalık varlığı ile anestezinin türü, ameliyatın süresi gibi birçok nedenlerle basınç yaralanması gelişme riski artmaktadır (16-22). Özellikle hastada ameliyat sırasında basınç yaralanması gelişimine basınç, sürtünme ve nem zemin hazırlamaktadır. Sürtünme, hastaya pozisyon verilmesi sırasında ve ameliyatın uzun sürmesi durumunda oluşmaktadır. Cildin aşırı nemi, cildin maserasyonuna ve doku hasarına yol açan kollajenin zayıflamasına veya cildin elastikiyetinin bozulmasına neden olmaktadır. Ek hastalığı bulunan cerrahi hastasının cildi, basınç ve sürtünmeden kaynaklanan hasara karşı daha hassas olabilmektedir. Kullanılan antiseptik solüsyonlar da hastanın cildinin pH'ını değiştirerek, koruyuculuğunu azaltmakta, maserasyon riskini arttırmaktadır (22,23). Bir metaanaliz çalışmasında basınç yaralanmalarının genellikle kalp, genel/torasik, ortopedik ve vasküler cerrahi girişimler sonrasında daha sı gelişebileceği bildirilmiştir (24). Cerrahi hastalarında basınç yaralanması gelişimi ağrının artmasına, hastanede daha uzun süre kalmaya, hastaneye tekrar yatışlara, çoklu cerrahi girişimlere ve olası şekil bozukluğuna neden olabilmektedir $(20,25)$.

Basınçyaralanmalarınınolumsuzetkileriniazaltmadariskfaktörlerinin, önleyici yaklaşımların doğru bilinmesi ve değerlendirilmesi ile olası doku hasarının erken tanılanmasının önemi büyüktür. Bu amaçla uluslararası basınç yaralanması ile ilgilenen kuruluşlar (European Pressure Ulcer Advisory Panel [EPUAP], National Pressure Injury Advisory Panel [NPUAP], Pan Pasific Pressure Injury Alliance [PPPIA]) her hastanın değerlendirmesinin yanı sıra, hastaya özel geçerli ve güvenilir risk ölçme araçları kullanılmasını, riskli hastaların önceden belirlenerek önlemlerin alınmasını önermektedir (8-19, 2629). Hastanın değerlendirilmesi ile bu yaralanmalara neden olabilecek faktörler belirlenebilmekte, riskleri azaltan önlemler alınarak basınç Genel Tip Derg 2021;31(2)168-174 yaralanmaları gelişimi azaltılabilmektedir. En önemlisi nokta, risk değerlendirmesiyle belirlenebilen faktörlerin birçoğunun hemşirelik girişimleriyle önlenmesidir (30-33). Ancak, basınç yaralanmaları gelişimi nedenlerinden birisinin de hemşirelerin bu konudaki bilgi eksikliği olduğu vurgulanmakta, çalışmaların çoğunun yoğun bakım hemşireleri üzerine yoğunlaşıldığ 1 , cerrahi süreçte yer alan cerrahi hemşirelerinin basınç yaralanmaları konusunda bilgilerini belirleyen çalışmaların sınırlı olduğu görülmektedir (33-38). Bu gerekçelerle, çalışmada süreçte yer alan (cerrahi klinik, ameliyathane ve cerrahi yoğun bakım) hemşirelerin basınç yaralanması, risk faktörleri ve önlemeye ilişkin bilgilerinin incelenmesi amaçlandı.

\section{Gereç ve Yöntem}

Tanımlayıcı nitelikte olan çalışma 01.05.2018-01.03.2019 tarihleri arasında Batı Karadeniz bölgesinde yer alan bir il merkezindeki Eğitim ve Araştırma, ilçe devlet hastanesi ile özel hastanede yapıldı. Çalışmanın evrenini cerrahi hastaları ile karşılaşan ve bakım veren ameliyathane, cerrahi klinikler ile cerrahi yoğun bakımda çalışan tüm hemşireler $(\mathrm{N}=400)$ oluşturdu. Tam sayım örnekleme yöntemi ile çalışmanın yapılacağı tarih aralığında izinli veya raporlu olmayan, katılıma istekli ve onam veren 245 cerrahi hemşiresi çalışma kapsamına alındı (Katılım oranı: \%63). Çalı̧̧ma verileri, "Kişisel Bilgi Formu" ve "Modifiye Pieper Basınç Yarası Bilgi Testi" ile iş akışını engellemeyecek zaman içerisinde toplandı ve her katılımcı için yaklaşık 20-25 dakika sürdü.

Kişisel Bilgi Formu: Bu form, hemşirelerin yaş, cinsiyet, medeni durumu, eğitim durumu, hizmet süresi, çalıştığı klinik, basınç yarası ile karşılaşma durumu ve sıklığını değerlendiren 21 sorudan oluştu.

Modifiye Pieper Basınç Yarası Bilgi Testi: Hemşirelerin bilgi düzeyini ölçmek amacıyla kullanılan bir bilgi testidir. Pieper ve Mott tarafından 1995 yılında geliştirilen ölçekte, önlem ve risk değerlendirilmesi, evrelendirme ve yara tanımını içeren toplam 47 ifade yer almaktadır (34). Her doğru yanıt ' 1 ', yanlış ve bilmiyorum yanıtları ' 0 ' olarak puanlanmaktadır. Lawrence ve ark. tarafindan 2015 yılında revize edilerek 49 ifadeye çıkarılmıştır. Testin yüzde değerleri, doğru cevaplar toplam soru sayısına bölünüp 100 ile çarpılması ile elde edilmekte, doğru yanıt oranı $>70$ orta, $>80 \%$ iyi, $90 \%$ çok iyi olduğunu göstermektedir (35). Gül ve Ark. benzer şekilde 49 sorudan oluşan bilgi testinin Türkçe geçerlik çalışmasını yapmıştır. Bilgi testinin ilk 33 sorusu önleme ve risk değerlendirilmesi, sonraki 9 soru basınç yarasının evrelendirilmesi, daha sonraki 7 soru ise yara tanımının değerlendirilmesi olmak üzere üç bölümden ve toplam 49 sorudan oluşmuş, Cronbach Alpha değeri 0.814 olarak bildirilmiştir (36). Çalışmamızda da Cronbach Alpha değeri 0.874 olarak bulunmuştur.

\section{İstatistiksel Analiz}

Çalışma verilerinin değerlendirilmesinde IBM SPSS Statistics 20 programı kullanıldı. Verilerin tanımlayıcı istatistiklerinde ortalama, standart sapma, Minumum Maksimum, Ortanca ve IQR değerleri kullanıldı. Karşılaştırmalarda Mann Whitney U testi, Kruskal Wallis Varyans analizinden yararlanıldı. Kruskal Wallis analizi sonucunda fark bulunan parametrelerde farklılı̆̆ı hangi grup ya da gruplarda kaynaklandığı Kruskal Wallis Varyans Analizi çoklu karşılaştırma testi ile incelendi. İstatistiksel anlamlılık sınırı olarak $\mathrm{p}<0,05$ kabul edildi.

\section{Araştırmanın Etik ve Yasal Yönü}

Çalışmaya ..... Üniversitesi Girişimsel Olmayan Klinik Araştırmalar

Cerrahi hemşire ve basınç yaralanması - Ünlü ve Andsoy. 
Etik Kurul'undan onam ve kurum izinleri alındıktan sonra başlandı. Hemşirelere herhangi bir zamanda, istendiği durumda sorumlu araştırmacıyı bilgilendirmek koşulu ile araştırmadan ayrılabilecekleri söylendi. Çalışma sırasında toplanan bilgiler araştırmacıda saklı kalacak şekilde veriler yalnızca bilimsel amaçla kullanıldı.

\section{Araştırmanın Sınırlılıkları}

Hemşirelerin çalışma saatlerindeki yoğunlukları, bilgi ölçtüğü için yetersizlik kaygısından dolayı anketleri doldurmalarındaki isteksizleri, yalnızca cerrahi hemşireleri kapsaması çalışmanın sınırlılıkları olarak düşünülmektedir.

\section{Bulgular}

Hemşirelerin örneklem için ortalama bilgi puanları $31.05 \pm 7.54$ idi. Toplam puan için PU bilgisi üzerinden \%63 puan almıştır. PU önleme / risk değerlendirmesi için 20,04 (\% 60.4), basınç yarasının evrelendirilmesi için $6.1(\% 68)$, yara tanımı için ise $4.8(\% 68,9)$ olduğu görüldü (Tablo 1).

Tablo 1. Hemşirelerin Modifiye Pieper Basınç Yarası Bilgi Testi Ortalama Puanları

\begin{tabular}{|l|l|l|l|}
\hline Bilgi Testi & Ort $\pm S S$ & $\begin{array}{l}\text { Ortanca } \\
\text { (Min-Max) }\end{array}$ & IQR \\
\hline Önleme ve risk değerlendirilmesi puan ort. & $20.04 \pm 4.87$ & $21(0-28)$ & 6 \\
\hline Basınç yarasının evrelendirilmesi puan ort. & $6.19 \pm 2.09$ & $7(0-9)$ & 3 \\
\hline Yara tanımını değerlendirilmesi puan ort. & $4.82 \pm 1.41$ & $5(0-7)$ & 2 \\
\hline Pieper basınç yarası bilgi ölçeği puan ort. & $31.05 \pm 7.54$ & $32(0-44)$ & 8 \\
\hline
\end{tabular}

Çalışmada, yoğun bakım, cerrahi klinikler ve ameliyathanede çalışan hemşirelerin önleme ve risk değerlendirmesi ile yara tanımından aldıkları puanlar arasında istatiksel olarak anlamlı fark bulundu $(p<0.01)$, yoğun bakımda çalışan hemşirelerin önleme ve risk değerlendirmesi ile yara tanımına yönelik verdikleri doğru yanıt puan ortalaması cerrahi kliniklerde çalışan hemşirelere göre anlamlı düzeyde yüksekti $(\mathrm{p}=0.004)$. Yine çalışmada, mesleği seçmekten memnun olan cerrahi hemşirelerin evrelendirme ve yara tanımına yönelik verdikleri doğru yanıt puan ortalamasının istatistiksel olarak yüksek $(\mathrm{p}<0.05)$, çalıştıkları birimde basınç yaralanması ile sık karşılaşan hemşirelerin de önleme ve risk ile evrelendirme konusunda doğru yanıt puan ortalamasının karşılaşmayanlara göre istatiksel olarak daha yüksek olduğu $(\mathrm{p}<0.001 ; \mathrm{p}<0.05)$, basınç yarası riskini değerlendirmek için ölçek kullanan hemşirelerin de benzer olarak önleme ve risk ile yara tanımı konusundaki doğru yanıt puan ortalamasının yüksek olduğu belirlendi $(\mathrm{p}<0.05)$. Ayrıca çalışmada, basınç yarasının önlemesinde mesleki bilgilerin, hasta ve ailesine verilen eğitimin etkin olduğuna inan hemşirelerin önleme ve risk ile yara tanımı konusundaki aldıkları doğru yanıt puan ortalamasının anlamlı düzeyde yüksek olduğu saptandı ( $\mathrm{p}<0.05 ; \mathrm{p}<0.01)$ (Tablo 2).

Tablo 2. Hemşirelere ait bazı değişkenler ile Modifiye Pieper Basınç Yarası Bilgi Testi Puanlarının Karşılaştırılması

\begin{tabular}{|c|c|c|c|c|}
\hline & Önleme -risk & Evrelendirme & Yara tanımı & Pieper Puan \\
\hline Değişkenler & $\begin{array}{l}\text { Ort } \pm S S \text { min-max } \\
\text { Median (IQR) }\end{array}$ & $\begin{array}{l}\text { Ort } \pm \text { SS min-max } \\
\text { Median (IQR) }\end{array}$ & $\begin{array}{l}\text { Ort } \pm S S \text { min-max } \\
\text { Median (IQR) }\end{array}$ & $\begin{array}{l}\text { Ort } \pm S S \text { min-max } \\
\text { Median (IQR) }\end{array}$ \\
\hline \multicolumn{5}{|l|}{ Eğitim Düzeyi } \\
\hline Sağılk meslek lisesi ( $\mathrm{n}=51)$ & $\begin{array}{l}20.41 \pm 5.57(0-26) \\
21(5)\end{array}$ & $\begin{array}{l}6.08 \pm 2.32(0-9) \\
7(3)\end{array}$ & $\begin{array}{l}4.80 \pm 1.62(0-7) \\
5(2)\end{array}$ & $\begin{array}{l}31.29 \pm 8.72(0-41) \\
33(8)\end{array}$ \\
\hline Ön Lisans (n=53) & $\begin{array}{l}19.66 \pm 5.06(3-28) \\
20(6)\end{array}$ & $\begin{array}{l}6.47 \pm 2.04(0-9) \\
7(3)\end{array}$ & $\begin{array}{l}4.92 \pm 1.16(1-7) \\
5(2)\end{array}$ & $\begin{array}{l}31.06 \pm 7.34(4-44) \\
32(8)\end{array}$ \\
\hline Lisans ( $\mathrm{n}=121)$ & $\begin{array}{l}19.84 \pm 4.66(0-28) \\
21(5)\end{array}$ & $\begin{array}{l}6.07 \pm 2.11(0-9) \\
7(3)\end{array}$ & $\begin{array}{l}4.71 \pm 1.43(0-7) \\
5(2)\end{array}$ & $\begin{array}{l}30.62 \pm 7.47(0-42) \\
32(9)\end{array}$ \\
\hline Y. Lisans $(\mathrm{n}=20)$ & $\begin{array}{l}21.30 \pm 3.63(14-27) \\
22(5.75)\end{array}$ & $\begin{array}{l}6.45 \pm 1.39(4-9) \\
6.5(2.5)\end{array}$ & $\begin{array}{l}5.30 \pm 1.22(2-7) \\
6(1.75)\end{array}$ & $\begin{array}{l}33.05 \pm 5.06 \quad 23-40) \\
34(7.75)\end{array}$ \\
\hline İstatistiksel Analiz & $\mathrm{KW}=3.625 ; 0.305$ & $\mathrm{KW}=1.274 ; 0.735$ & $\mathrm{KW}=3.979 ; 0.264$ & $\mathrm{KW}=2.542 ; 0.468$ \\
\hline \multicolumn{5}{|l|}{ Mesleki deneyim } \\
\hline $1-5$ yl $(\mathrm{n}=73)$ & $\begin{array}{l}20.79 \pm 4.98(0-28) \\
21(5)\end{array}$ & $\begin{array}{l}6.03 \pm 2.19(0-9) \\
7(3)\end{array}$ & $\begin{array}{l}4.82 \pm 1.47(0-7) \\
5(2)\end{array}$ & $\begin{array}{l}31.64 \pm 7.84(0-42) \\
34(7.5)\end{array}$ \\
\hline $6-10$ yil $(\mathrm{n}=43)$ & $\begin{array}{l}19.28 \pm 5.37(0-28) \\
20(5) \\
\end{array}$ & $\begin{array}{l}6.14 \pm 1.71(0-8) \\
6(2) \\
\end{array}$ & $\begin{array}{l}4.81 \pm 1.24(0-7) \\
5(2)\end{array}$ & $\begin{array}{l}30.23 \pm 7.68(0-42) \\
31(7) \\
\end{array}$ \\
\hline $11-15$ yll $(\mathrm{n}=30)$ & $\begin{array}{l}21.03 \pm 3.75(14-26) \\
20(6.5) \\
\end{array}$ & $\begin{array}{l}6.30 \pm 2.18(1-9) \\
6.5(3)\end{array}$ & $\begin{array}{l}5.17 \pm 1.12(3-7) \\
5(2)\end{array}$ & $\begin{array}{l}32.50 \pm 6.38(2-45) \\
32(11.5)\end{array}$ \\
\hline $16-20$ yil $(\mathrm{n}=47)$ & $\begin{array}{l}19.06 \pm 4.61(5-26) \\
19(5)\end{array}$ & $\begin{array}{l}6.62 \pm 1.88(2-9) \\
7(3)\end{array}$ & $\begin{array}{l}4.66 \pm 1.31(2-7) \\
5(1)\end{array}$ & $\begin{array}{l}30.34 \pm 6.88(11-40) \\
32(10)\end{array}$ \\
\hline
\end{tabular}




\begin{tabular}{|c|c|c|c|c|}
\hline 20 yıl üzeri (n=52) & $\begin{array}{l}19.92 \pm 4.98(3-28) \\
21(5)\end{array}$ & $\begin{array}{l}6.00 \pm 2.36(0-9) \\
6(3)\end{array}$ & $\begin{array}{l}4.79 \pm 1.67(0-7) \\
5(2)\end{array}$ & $\begin{array}{l}30.71 \pm 8.26(4-44) \\
33(8.75)\end{array}$ \\
\hline Test istatistiği & $\mathrm{KW}=7.990 ; 0.092$ & $\mathrm{KW}=2.739 ; 0.602$ & $\mathrm{KW}=3.027 ; 0.553$ & $\mathrm{KW}=3.469 ; 0.483$ \\
\hline \multicolumn{5}{|l|}{ Çalıştı̆ı Klinik } \\
\hline Yoğun Bakım (n=76) & $\begin{array}{l}21.05 \pm 4.37(0-28) \\
22(5)\end{array}$ & $\begin{array}{l}6.31 \pm 2.00(0-9) \\
7(3)\end{array}$ & $\begin{array}{l}5.10 \pm 1.28(0-7) \\
5(1)\end{array}$ & $\begin{array}{l}32.47 \pm 6.79(0-42) \\
34(7.75)\end{array}$ \\
\hline Cerrahi klinikler $(\mathrm{n}=114)$ & $\begin{array}{l}18.87 \pm 5.42(0-28) \\
20(6.25)\end{array}$ & $\begin{array}{l}5.83 \pm 2.31(0-9) \\
6(2.25)\end{array}$ & $\begin{array}{l}4.59 \pm 1.59(0-7) \\
5(2)\end{array}$ & $\begin{array}{l}29.29 \pm 8.50(0-42) \\
31(9)\end{array}$ \\
\hline Ameliyathane $(\mathrm{n}=55)$ & $\begin{array}{l}21.07 \pm 3.71(9-28) \\
21(6)\end{array}$ & $\begin{array}{l}6.74 \pm 1.55(3-9) \\
7(2)\end{array}$ & $\begin{array}{l}4.93 \pm 1.07(3-7) \\
5(2)\end{array}$ & $\begin{array}{l}32.75 \pm 5.44(16-44) \\
33(8)\end{array}$ \\
\hline İstatistiksel Analiz & $\mathrm{KW}=11.076 ; 0.004$ & $\mathrm{KW}=5.407 ; 0.067$ & $\mathrm{KW}=7.780 ; 0.020$ & $\mathrm{KW}=10.352 ; 0.006$ \\
\hline & $\begin{array}{l}.007 \\
p=1.000 \\
e=0.059\end{array}$ & $\begin{array}{l}\text { rahi } \mathrm{p}=0.016 \\
\text { neliyat. } \mathrm{p}=0.441 \\
\text { eliyat. } \mathrm{p}=1.000 \quad \mathrm{Ce}\end{array}$ & $\begin{array}{l}0.016 \\
p=0.441 \\
=1.000\end{array}$ & \\
\hline \multicolumn{5}{|c|}{ Meslek seçmede memnuniyet } \\
\hline Evet $(n=174)$ & $\begin{array}{l}20.49 \pm 4.27(3-28) \\
21(6)\end{array}$ & $\begin{array}{l}6.36 \pm 2.04(0-9) \\
7(3)\end{array}$ & \begin{tabular}{|l}
$4.96 \pm 1.35(0-7)$ \\
$5(2)$
\end{tabular} & $\begin{array}{l}31.82 \pm 6.74(4-44) \\
33(9)\end{array}$ \\
\hline Hayır $(\mathrm{n}=71)$ & $\begin{array}{l}18.94 \pm 5.98(0-26) \\
20(6)\end{array}$ & $\begin{array}{l}5.76 \pm 2.17(0-9) \\
6(2)\end{array}$ & $\begin{array}{l}4.48 \pm 1.48(0-7) \\
5(1)\end{array}$ & $\begin{array}{l}29.18 \pm 9.00(0-39) \\
31(9)\end{array}$ \\
\hline İstatistiksel Analiz & $\mathrm{U}=5455.5 ; 0.150$ & $\mathrm{U}=5118.5 ; 0.033$ & $\mathrm{U}=5048.5 ; 0.020$ & $\mathrm{U}=5219.5 ; 0.057$ \\
\hline \multicolumn{5}{|c|}{ BY'sının önlenmesini hemşirenin sorumluluğunda olduğunu düşünme } \\
\hline Evet $(\mathrm{n}=208)$ & $\begin{array}{l}20.23 \pm 4.77(0-28) \\
21(6)\end{array}$ & $\begin{array}{l}6.24 \pm 2.06(0-9) \\
7(3)\end{array}$ & $\begin{array}{l}4.88 \pm 1.41(0-7) \\
5(2)\end{array}$ & $\begin{array}{l}31.34 \pm 7.40(0-44) \\
33(8)\end{array}$ \\
\hline Hayır $(n=37)$ & $\begin{array}{l}19.00 \pm 5.32(4-28) \\
18(6.5)\end{array}$ & $\begin{array}{l}5.92 \pm 2.28(0-9) \\
6(3)\end{array}$ & \begin{tabular}{|l}
$4.51 \pm 1.37(0-7)$ \\
$5(1.5)$
\end{tabular} & $\begin{array}{l}29.43 \pm 8.21(4-42) \\
29(11)\end{array}$ \\
\hline Test istatistiği & $\mathrm{U}=3204.5 ; 0.104$ & $\mathrm{U}=3532.5 ; 0.420$ & $\mathrm{U}=3184.0 ; 0.083$ & $\mathrm{U}=3226.0 ; 0.117$ \\
\hline \multicolumn{5}{|c|}{ Çalışılan birimde basınç yaralanması ile sık karşılaşma } \\
\hline Evet $(\mathrm{n}=55)$ & $\begin{array}{l}22.07 \pm 2.81(13-26) \\
23(4)\end{array}$ & $\begin{array}{l}6.80 \pm 1.66(2-9) \\
7(2) \\
\end{array}$ & $\begin{array}{l}5.13 \pm 1.02(3-7) \\
5(1) \\
\end{array}$ & $\begin{array}{l}34.00 \pm 4.32(18-40) \\
35(5)\end{array}$ \\
\hline Hayır $(\mathrm{n}=190)$ & $\begin{array}{l}19.45 \pm 5.18(0-28) \\
20(6)\end{array}$ & $\begin{array}{l}6.01 \pm 2.17(0-9) \\
6(3) \\
\end{array}$ & \begin{tabular}{|l}
$4.74 \pm 1.49(0-7)$ \\
$5(2)$ \\
\end{tabular} & $\begin{array}{l}30.20 \pm 8.06(0-44) \\
31(9)\end{array}$ \\
\hline İstatistiksel Analiz & $\mathrm{U}=3516.5 ; 0.000$ & $\mathrm{U}=4147.0 ; 0.018$ & $\mathrm{U}=4502.5 ; 0.106$ & $\mathrm{U}=3664.0 ; 0.001$ \\
\hline \multicolumn{5}{|c|}{ Haftada bakım verilen basinç yarası olan hasta sayısı } \\
\hline $1-2$ hasta $(\mathrm{n}=39)$ & $\begin{array}{l}22.15 \pm 2.72(15-26) \\
23(4)\end{array}$ & $\begin{array}{l}6.82 \pm 1.65(2-9) \\
7(2)\end{array}$ & \begin{tabular}{|l}
$5.18 \pm 0.79(3-7)$ \\
$5(1)$ \\
\end{tabular} & $\begin{array}{l}34.15 \pm 3.83(26-40) \\
35(5) \\
\end{array}$ \\
\hline $3-4$ hasta $(\mathrm{n}=10)$ & $\begin{array}{l}21.60 \pm 3.89(13-25) \\
22.5(5.5)\end{array}$ & $\begin{array}{l}6.10 \pm 1.85(3-8) \\
6.5(4) \\
\end{array}$ & \begin{tabular}{|l|}
$5.20 \pm 1.69(2-7)$ \\
$6(2.5)$ \\
\end{tabular} & $\begin{array}{l}32.90 \pm 6.67(18-39) \\
35(9.5)\end{array}$ \\
\hline 5 ve üzeri hasta $(\mathrm{n}=6)$ & $\begin{array}{l}22.33 \pm 1.21(21-24) \\
22.5(2.25)\end{array}$ & $\begin{array}{l}7.83 \pm 0.75(7-9) \\
8(1.25)\end{array}$ & $\begin{array}{l}4.67 \pm 1.03(4-6) \\
4(2)\end{array}$ & $\begin{array}{l}34.83 \pm 2.48 \quad(32-39) \\
34.5(4)\end{array}$ \\
\hline İstatistiksel Analiz & $\mathrm{KW}=0.011 ; 0.995$ & $\mathrm{KW}=4.202 ; 0.122$ & $\mathrm{KW}=2.220 ; 0.330$ & $\mathrm{KW}=0.030 ; 0.985$ \\
\hline \multicolumn{5}{|l|}{ Ölçek kullanma } \\
\hline Evet $(\mathrm{n}=133)$ & $\begin{array}{l}20.68 \pm 4.51(0-28) \\
21(5)\end{array}$ & $\begin{array}{l}6.22 \pm 1.93(0-9) \\
7(3)\end{array}$ & $\begin{array}{l}4.99 \pm 1.36(0-7) \\
5(2)\end{array}$ & $\begin{array}{l}31.89 \pm 6.96(0-42) \\
33(7.5)\end{array}$ \\
\hline Hayir (n=112) & $\begin{array}{l}19.29 \pm 5.18(0-28) \\
20(6)\end{array}$ & $\begin{array}{l}6.15 \pm 2.27(0-9) \\
7(3) \\
\end{array}$ & \begin{tabular}{|l|}
$4.62 \pm 1.44(0-7)$ \\
$5(1)$ \\
\end{tabular} & $\begin{array}{l}30.06 \pm 8.10(0-44) \\
31(9)\end{array}$ \\
\hline İstatistiksel Analiz & $\mathrm{U}=6144.5 ; 0.018$ & $\mathrm{U}=7365.0 ; 0.879$ & $\mathrm{U}=6160.5 ; 0.016$ & $\mathrm{U}=6432.0 ; 0.066$ \\
\hline \multicolumn{5}{|c|}{ BY'ssmın önlenmesinde mesleki bilgilerin, hasta ve ailesinin eğitilmesinin etkin olduğuna inanma } \\
\hline Evet $(\mathrm{n}=169)$ & $\begin{array}{l}20.75 \pm 4.08(0-28) \\
21(6)\end{array}$ & $\begin{array}{l}6.39 \pm 1.84(0-9) \\
7(3)\end{array}$ & \begin{tabular}{|l}
$5.01 \pm 1.27(0-7)$ \\
$5(2)$
\end{tabular} & $\begin{array}{l}32.15 \pm 6.29(0-44) \\
33(7)\end{array}$ \\
\hline Hayir $(\mathrm{n}=76)$ & $\begin{array}{l}18.46 \pm 6.01(0-27) \\
20(8)\end{array}$ & $\begin{array}{l}5.74 \pm 2.51(0-9) \\
6(4)\end{array}$ & $\begin{array}{l}4.42 \pm 1.61(0-7) \\
5(1)\end{array}$ & $\begin{array}{l}28.62 \pm 9.38(0-41) \\
30.5(14)\end{array}$ \\
\hline İstatistiksel Analiz & $\mathrm{U}=5106.5 ; 0.010$ & $\mathrm{U}=5660.5 ; 0.132$ & $\mathrm{U}=5026.5 ; 0.005$ & $\mathrm{U}=5205.5 ; 0.018$ \\
\hline
\end{tabular}

BY: Basınç Yaralanması, KW: Kruskall Wallis Testi, U: Mann Whitney U Testi 
Cerrahi hemşirelerin basınç yaralanmasına yönelik aldıkları eğitim ve ilgili bazı değişkenler ile Modifiye Pieper Basınç Yarası Bilgi Testinin doğru puan ortalaması karşılaștırılmaları Tablo 4' te gösterildi. Basınç yaralanmalarına ilișkin hizmetiçi eğitime katılann hemşirelerin önleme ve risk, evrelendirme ile yara tanımı konusuna verdikleri doğru yanıt puan ortalamasının istatistiksel olarak daha yüksek olduğu belirlendi $(\mathrm{p}<0.05)$. Çalışmada, basınç yaralanmalarına yönelik makale okuyan, internetten araştıran hemşirelerin önleme ve risk ile yara tanımına verdikleri doğru yanıt puan ortalamasının istatistiksel olarak yüksek olduğu görüldü $(\mathrm{p}<0.05)$.

Tablo 3. Hizmetiçi Eğitim ve ilgili değişkenler ile Modifiye Pieper Basınç Yarası Bilgi Testi Puanlarının Karşılaştırılması

\begin{tabular}{|c|c|c|c|c|}
\hline \multirow[t]{2}{*}{ Değişkenler } & Önleme ve risk & Evrelendirme & Yara tanımı & Pieper Puan \\
\hline & $\begin{array}{l}\text { Ort } \pm \text { SS min-max } \\
\text { Median (IQR) }\end{array}$ & $\begin{array}{l}\text { Ort } \pm \text { SS min-max } \\
\text { Median (IQR) }\end{array}$ & $\begin{array}{l}\text { Ort } \pm \text { SS min-max } \\
\text { Median (IQR) }\end{array}$ & $\begin{array}{l}\text { Ort } \pm \text { SS min-max } \\
\text { Median (IQR) }\end{array}$ \\
\hline \multicolumn{5}{|c|}{ Hizmet içi eğitime katılma } \\
\hline Evet $(n=172)$ & $\begin{array}{l}20.43 \pm 4.86(0-28) \\
26(6)\end{array}$ & $\begin{array}{l}6.37 \pm 2.04(0-7) \\
7(2)\end{array}$ & $\begin{array}{l}4.93 \pm 1.40(0-7) \\
5(2)\end{array}$ & $\begin{array}{l}31.73 \pm 7.55(0-44) \\
33(8)\end{array}$ \\
\hline Hayır $(\mathrm{n}=73)$ & $\begin{array}{l}19.12 \pm 4.79(3-26) \\
20(5.5)\end{array}$ & $\begin{array}{l}5.77 \pm 2.15(0-9) \\
6(4)\end{array}$ & $\begin{array}{l}4.57 \pm 1.39(0-7) \\
5(1)\end{array}$ & $\begin{array}{l}29.47 \pm 7.33(4-41) \\
30(9)\end{array}$ \\
\hline İstatistiksel Analiz & $\mathrm{U}=5135.0 ; 0.024$ & $\mathrm{U}=5146.5 ; 0.023$ & $\mathrm{U}=5262.5 ; 0.038$ & $\mathrm{U}=4822.5 ; 0.004$ \\
\hline \multicolumn{5}{|c|}{ Eğitimleri hemşirelik bakımına yansıtma } \\
\hline Evet $(n=167)$ & $\begin{array}{l}20.35 \pm 4.91(0-28) \\
21(6)\end{array}$ & $\begin{array}{l}6.35 \pm 2.07(0-9) \\
7(2)\end{array}$ & $\begin{array}{l}4.95 \pm 1.42(0-7) \\
5(2)\end{array}$ & $\begin{array}{l}31.65 \pm 7.65(0-44) \\
33(8)\end{array}$ \\
\hline Hayır $(n=5)$ & $\begin{array}{l}23.20 \pm 1.30(21-24) \\
24(2)\end{array}$ & $\begin{array}{l}6.80 \pm 0.84(6-8) \\
7(1.5)\end{array}$ & $\begin{array}{l}4.40 \pm 0.55 \text { (4-5) } \\
4(1)\end{array}$ & $\begin{array}{l}34.40 \pm 2.41 \quad(31-37) \\
35(4.5)\end{array}$ \\
\hline İstatistiksel Analiz & $\mathrm{U}=247.0 ; 0.119$ & $\mathrm{U}=410.5 ; 0.948$ & $\mathrm{U}=254.5 ; 0.123$ & $\mathrm{U}=340.5 ; 0.482$ \\
\hline \multicolumn{5}{|c|}{ BY'na yönelik makale okuma, internetten araştırma yapma } \\
\hline Evet $(n=87)$ & $\begin{array}{l}21.11 \pm 3.34(9-28) \\
21(5)\end{array}$ & $\begin{array}{l}6.57 \pm 1.65(2-9) \\
7(2)\end{array}$ & $\begin{array}{l}5.10 \pm 1.12(2-7) \\
5(1)\end{array}$ & $\begin{array}{l}32.79 \pm 4.88(16-44) \\
33(7)\end{array}$ \\
\hline Hayır $(\mathrm{n}=158)$ & $\begin{array}{l}19.45 \pm 5.45(0-28) \\
21(6)\end{array}$ & $\begin{array}{l}5.97 \pm 2.27(0-9) \\
6(3)\end{array}$ & $\begin{array}{l}4.67 \pm 1.52(0-7) \\
5(2)\end{array}$ & $\begin{array}{l}30.09 \pm 8.53(0-42) \\
31(9)\end{array}$ \\
\hline İstatistiksel Analiz & $\mathrm{U}=5801.0 ; 0.043$ & $\mathrm{U}=6022.5 ; 0.103$ & $\mathrm{U}=5798.0 ; 0.036$ & $\mathrm{U}=5818.5 ; 0.047$ \\
\hline \multicolumn{5}{|c|}{ BY'sını önleme/tedaviye yönelik gelişmeleri takip etme } \\
\hline Evet $(n=15)$ & $\begin{array}{l}20.60 \pm 3.38(13-26) \\
20(4)\end{array}$ & $\begin{array}{l}6.00 \pm 2.45(0-8) \\
7(3)\end{array}$ & $\begin{array}{l}4.93 \pm 0.79(3-6) \\
5(0)\end{array}$ & $\begin{array}{l}31.53 \pm 5.65(18-44) \\
32(9)\end{array}$ \\
\hline Hayır $(\mathrm{n}=230)$ & $\begin{array}{l}20.00 \pm 4.95(0-28) \\
21(6)\end{array}$ & $\begin{array}{l}6.20 \pm 2.04(0-9) \\
7(3)\end{array}$ & $\begin{array}{l}4.82 \pm 1.44(0-7) \\
5(2)\end{array}$ & $\begin{array}{l}31.02 \pm 7.66(0-44) \\
32(8)\end{array}$ \\
\hline İstatistiksel Analiz & $\mathrm{U}=257.0 ; 0.940$ & $\mathrm{U}=417.5 ; 0.985$ & $\mathrm{U}=409.5 ; 0.995$ & $\mathrm{U}=310.5 ; 0.904$ \\
\hline
\end{tabular}

BY: Basınç Yaralanması, KW: Kruskall Wallis Testi, U: Mann Whitney U Testi

\section{Tartışma}

Basınç yaralanmaları, sağlı sunumundaki gelişme ve yeniliklere karşın, hasta, sağlık çalışanları ile kurumlar açısından önemli bir sorun olarak görülmekte ve hala güncelliğini korumaktadır $(2,3,9,19,20)$. Günümüzde basınç yaralanmalarına neden olabilecek risk faktörlerin belirlenmesi hemşireler tarafından yapılmakla birlikte, cerrahi hastalarında oluşabilecek yaralanmalarda önleyici girişimlerin erken dönemde başlatılması gerekmektedir. Literatürde basınç yaralanması gelişim nedenlerinden birisinin de hemşirelerin bu konudaki bilgi eksikliği olduğu vurgulanmaktadır $(32,33)$. Dolayısıyla hemşirelerinin basınç yaralanması risk faktörleri ve önlemeye ilişkin yeterli bilgiye sahip olması gerekmektedir $(7,22,31,33)$.

Mevcut bazı kanıtlar, daha etkili stratejilerin yapılması, etkili ve bilinçli önlemlerin alınması basınç yaralanmaları prevalansının ve insidansının son 10 yılda azaldığını göstermiştir (39). Bu stratejierden birisi de basınç yaralanmaları ile ilgili bilgidüzenlenmesidir. Çalışmada cerrahi süreçte (klinik, ameliyathane ve cerrahi yoğun bakım) yer alan hemşirelerin Modifiye Pieper Basınç Yarası Bilgi Testi doğru yanıt ortalamasının orta düzeyin altında (\%63) olduğu görülmüştür. Cerrahi hemşirelerin en fazla doğru yanıt ortalamasının yara tanımı, evrelendirme en az doğru yanıt ortalamasının ise önleme ve risk değerlendirilmesine yönelik olduğu belirlenmiştir (Tablo 1). Gül ve ark. (2017)’1 bulgumuza paralel olarak hemşirelerin basınç yaralanması önleme ve risk, yara tanımlaması ve evrelendirme (sırasılya; \%60, \%56, \%6) bilgi düzeyini orta düzeyin altında bulmuşlardır (36). Başka bir çalışmada hemşirelerin en düşük puanı yara tanımında, yüksek skoru ise önleme konusunda aldığı belirlenmesine karşın (37), Quaddumi ve Khawaldeh (2014), Awali ve ark. (2012) ve Rocha ve ark. (2015) hemşirelerin etyoloji, evrelendirme, önleme ve risk değerlendirmesi konusunda bilgi puan ortalamasının çok düşük olduğunu (40-42), birçok çalışmada da benzer olarak hemşirelerin basınç yaralanmasına yönelik bilgi durumunun istendik düzeyde olmadığı bulunmuştur (43, 44-46). Bu bulguların aksine hemşirelerin basınç yarasının önlenmesi ve risk faktörlerine yönelik bilgilerinin yeterli olduğunu bildiren çalışmalarda bulunmaktadır $(38,47,48)$. Çalışmamız 
da farklı olarak hemşirelerin en fazla doğru yanıt ortalamasının yara tanımı ve evrelendirmede olduğu görülmüştür. Bu sonuç bize cerrahi hemşirelerin hizmetiçi eğitim kapsamında bilgilerinin hala güncel olabileceğini düşündürmüştür.

Çalışmada hemşirelerin eğitim durumu, mesleki deneyim ile önleme ve risk, evrelendirme ile yara tanımına verdikleri doğru yanıt ortalaması arasında fark bulunmamıştır (Tablo 2). Bazı çalışmalarda bulgumuz ile uyumlu olarak hemşirelerin eğitim durumu ile basınç yaralanmalarına yönelik bilgi puanı arasında bir fark belirlenmezken $(33,43,47,48)$, Alsharari ve ark. (2017) hemşirelerin eğitim durumu ile doğru yanıt oranı arasındaki korelasyonun düşük olduğu (5), Aydın ve Karadağ (2010), Aydın ve ark (2019) ile Lawrence ve ark (2015) çalışmalarında ise hemşirelerin eğitim düzeyi ile bilgi puan ortalaması arasında anlamlı ilişki bulunmuştur $(35,49,50)$.

Cerrahi hemşirelerin hizmet süresi ile Modifiye Pieper Basınç Yarası Bilgi Testi'nden aldıkları toplam puan ortalamaları arasında anlamlı bir fark bulunmamıştır (Tablo 2). Bulgumuzun aksine Nuru ve ark. (2015), 11-20 yıllık meslek deneyimine sahip hemşirelerin daha az deneyimli hemşirelere göre bilgi seviyesinin yüksek olduğu (38), Alsharari ve ark. (2017) ile Lawrence ve ark (2015) çalışmalarında deneyimli hemşirelerin genç hemşirelere göre daha iyi basınç yaralanması bilgisine sahip olduğunu, yaş ve deneyimle birlikte önleme bilgisinin arttığını $(5,35)$, diğer yandan Quaddumi ve Khawaldeh (2014) ile Çelik ve ark (2017) bulgumuza benzer olarak klinik deneyimin hemşirelerin bilgi durumunu etkilemediğini belirlemişlerdir $(33,40)$. $\mathrm{Bu}$ sonuç bize eğitim durumu ve hizmet süresi ne olursa olsun cerrahi hemşirelerin olanak ve koşullar dahilinde basınç yaralanması riski olan hastalara aynı hemşirelik bakımı yaptıklarını akla getirmiştir.

Çalışmada yoğun bakımda çalışan hemşirelerin Modifiye Pieper Basınç Yarası Bilgi Testi, önleme ve risk ile yara tanımından aldıkları puan ortalamasının cerrahi kliniklerde çalışan hemşirelere göre istatiksel olarak yüksek olduğu bulunmuştur (Tablo 2). Iranmanesh ve ark. (2017), Aydın ve ark. (2019), Chianca ve ark (2010) ile Alsharari ve ark (2017)'nin çalışmalarında yoğun bakımda çalışan hemşirelerin diğer kliniklerdeki hemşirelere göre daha bilgili oldukları bulunmuştur $(5,50,51,52)$. Literatürde de basınç yaralanması ile sık karşılaşılan kliniklerin başında, uzun süre yatan hastalara bakım verilen yoğun bakım üniteleri olduğu belirtilmektedir $(2,3,6,10,16,18)$. Bu doğrultuda çalışma bulgusunun literatür ve yapılan çalışma sonuçlarını destekler nitelikte uyumlu olduğu görülmüştür.

Çalışmamızda ölçek kullanan ve basınç yaralanmalarının önlenmesinde mesleki bilgilerin, hasta ve ailesinin eğitilmesinin etkin olduğuna inanan cerrahi hemşirelerin basınç yaralanmaları önleme ve risk ile yara tanımına yönelik verdikleri doğru yanıt ortalaması istatistiksel olarak yüksekti. Samuriwo ve Dowding (2014), hemşirelerin risk belirlenmesinde ölçekleri rutin olarak kullanmadığ 1 , hemşirelerin ölçek yerine kendi bilgi ve deneyimlerinden yararlandığ belirlenmiştir (53). Cerrahi hemşireleri arasında ölçek kullanan grubun bilgilerinin daha iyi durumda olması beklenen bir sonuçtur.

Çalışmamızda basınç yaralanması konusunda hizmet içi eğitim alan, makale okuyan ve internetten araştırma yapan cerrahi hemşirelerin doğru yanıt ortalamasının istatistiksel olarak yüksek olduğu belirlenmiştir (Tablo 3). Fulbrook ve ark (2019) ile Awali ve ark (2018)'nın çalışmalarında farklı olarak makale okuma, seminer ya da workshopa katılma ile basınç yaralanması bilgi puanları arasında bir ilişki belirlenmezken (37, 41), Quaddumi ve Khawaldeh (2014), Etafa ve ark (2018) araştırma yapan ve makale okuyan hemşirelerin daha fazla bilgiye sahip olmasına karşın, aynı çalışmada hizmet içi eğitime katılan hemşirelerin bilgi durumlarında bir değişiklik saptanmamıştır

Genel Tip Derg 2021;31(2)168-174
$(40,43)$. Diğer yandan, başka çalı̧̧malarda hizmetiçi eğitim alan hemşirelerin basınç yaralanmalarına ilişkin bilgilerinin anlamlı olarak yüksek olduğu bulunmuş ve çalışma bulgumuz ile paralellik göstermiştir (33, 38,48, 44,49,50). Hizmet içi eğitim, hizmette etkinliğin, verimin, kalitenin yükseltilmesi, hataların ve kazaların azaltılması, maliyetlerin düşürülmesi amacıyla bilgi, beceri, davranış ve verim düzeyini yükseltici plânlı eğitim etkinlikleridir. Dolayısıyla, bu eğitimlerle bilgilerin son kanttlar doğrultusunda güncellemesine katkıda bulunulmaktadır $(32,41)$. Çalışmamızda da basınç yaralanmasına yönelik hizmet içi eğitim alan cerrahi hemşirelerin puan ortalamasının yüksek olması, bu eğitimlerin hemşirelerin bilgilerinin güncellenmesine katkı sağladığını düşündürmüştür.

Sonuç olarak, çalışmada cerrahi süreçte yer alan hemşirelerin basınç yaralanması bilgisinin orta düzeyin altında $(>\% 70)$, en yüksek oranda doğru yanıt verdikleri konuların sırasıyla yara tanımı, evrelendirilmesi, önleme ve risk değerlendirilmesi olduğu belirlendi. Yine çalışmada cerrahi hemşirelerin basınç yaralanması bilgi testi puanlarının çalışılan klinik, basınç yaralanması ile karşılaşma, ölçek kullanma, mesleki bilgilerin ve hasta ile ailesinin etkin olduğuna inanma, hizmet içi eğitime katılma, basınç yaralanmasına yönelik makale okuma veya araştırma yapma durumları arasında anlamlı farklılık olduğu bulundu. Bu doğrultuda; cerrahi klinikler, yoğun bakım ile ameliyathanelerde çalışan cerrahi hemşirelere basınç yaralamasına yönelik hizmet içi eğitimlerin planlaması, hemşirelerin bilimsel toplantılara katılımına ve araştırma yapmaya teşvik etmek önerilebilir.

\section{Kaynaklar}

1. Esen O, Öncül S, Yılmaz M, Esen HK. Retrospective evaluation of pressure sores of patients in intensive care. Kartal Eğitim ve Araștırma Hastanesi Tıp Dergisi 2016; 27:111-15.

2. Shahin ESM, Dassen T, Halfens RJG. Incidence, prevention and treatment of pressure ulcers in intensive care patients: A longitudinal study. International Journal of Nursing Studies 2019; 46:413-21.

3. Tanrikulu F, Dikmen Y. Yoğun bakım hastalarında basınç yaraları: Risk faktörleri ve önlemler. Journal of Human Rhythm 2017; 3:177-82.

4. Korkmaz F, Uçar H. Topikal negatif basınç terapisinin III. ve IV. evre basınç yaralarının iyileşmesine etkisi. Hemşirelikte Araştırma Geliştirme Dergisi 2014;16:2837.

5. Alsharari FA, Khadam QA, Albagawi BS, Alotaibi JS, Alqahtani ME. Nurses' knowledge, attitudes and beliefs toward pressure ulcers prevention. Aljouf University Medical Journal 2017; 4 :21-8.

6. Cremasco MF, Wenzel F, Zanei, SS, Whitaker, IY. Pressure ulcers in the intensive care unit: The relationship between nursing workload, illness severity and pressure ulcer risk. Journal of Clinical Nursing 2013; 22:2183-91.

7. Gül Ş. Cerrahi Girişim Uygulanan Hastalarda Basınç Ülseri Gelişiminin Önlenmesi. Hacettepe Üniversitesi Hemşire Fakültesi Dergisi 2015; 1:54-61.

8. National Pressure Ulcer Advisory Panel. (2017). Available from:http://www.npuap. org/resources/educational-and-clinical-resources/2017-world-wide-pressure-injury-prevention-day/

9. Agengy for Healthcare Research and Quality. (2014). PreventingPressure Ulcers in Hospitals USA: U.S. Department of Health \& Human Services. Available from:https://www.ahrq.gov/professionals/systems/hospital/pressureulcertoolkit/putool1. html.

10. Becker D, Tozo, TC, Batista, SS, Mattos, AL, Silva MCB, Rigon, S, Duarte PA. Pressure ulcers in ICU patients: Incidence and clinical and epidemiological features: A multicenter study in southern Brazil. Intensive and Critical Care Nursing 2017; 42:55-61.

11. Rashvand F, Shamekhi L, Rafiei H, Nosrataghaei M. Incidence and risk factors for medical device-related pressure ulcers: The first report in this regard in Iran. International Wound Journal 2019; 12:11-17.

12. Gao, L, Yang L, Li X, Chen J, Du J, Yang H. Risk factors for intraoperative pressure ulcers in surgical patients, Int J Clin Exp Med 2018; 11(7):7429-35.

13. El-Marsi J, Zein-El-Dine S, Zein B, Doumit R, Kurdahi Badr L. Predictors of pressure injuries in a critical care unit in Lebanon: Prevalence, characteristics, and associated factors. Journal of Wound, Ostomy and Continence Nursing 2018; 45:131-36.

14. Kaşıçı $\mathrm{M}, \mathrm{Aksoy} \mathrm{M}, \mathrm{Ay}$ E. Investigation of the prevalence of pressure ulcers and patient-related risk factors in hospitals in the province of Erzurum: A cross-sectional study. Journal of Tissue Viability 2018; 27:135-40.

15. Karadag M, Gümüskaya N. The incidence of pressure ulcers in surgical patients: A 
sample hospital in Turkey. Journal of Clinical Nursing 2006; 15:413-21.

16. Katran HB. The research on the incidence of pressure sores in a surgical intensive care unit and the risk factors affecting the development of pressure sores. Journal of Academic Research In Nursing 2015; 1:8-14.

17. Walton-Geer PS. Prevention of Pressure Ulcers in the Surgical Patient, AORN J 2009;89(3):538-48;

18. Kıraner E, Terzi B, Ekinci, AU, Tunalı B. Yoğun bakım ünitemizdeki basınç yaras1 insidansı ve risk faktörlerinin belirlenmesi. Yoğun Bakım Hemşireliği Dergis 2016; 20:78-83.

19. Edsberg LE, Siyah JM, Goldberg M., McNichol L., Moore L, Sieggreen M. Revised National Pressure Ulcer Advisory Panel pressure injury staging system: revised pressure injury staging system. Journal of Wound, Ostomy, and Continence Nursing 2016; 43:585-97.

20. Association of Perioperative Registered Nurses.Position statement on perioperative pressure ulcer prevention in the care of the surgical patient. AORN Journal 2016; 104(5):437-38.

21. Soyer Ö, Özbayir T. 3S Ameliyathane basınç yarası risk tanılama ölçeğinin türkçeye uyarlanması. Uluslararası Hakemli Hemşirelik Araştırmaları Dergisi 2018; $13: 46-64$

22. Spruce L. Back to basics: Preventing perioperative pressure injuries. AORN Journal 2017; 105:92-99.

23. Giachetta-Ryan D. Perioperative pressure ulcers: How can they be prevented? OR Nurse 2015;9(4):22 - 28

24. He W, Liu P, Chen, HL. The braden scale can't be used alone for assessing pressure ulcer risk in surgical patients: A meta-analysis. Ostomy-Wound Management 2012; 58(2):34-40.

25. Wang I, Walker R, Gillespie BM. Pressure injury prevention in the perioperative setting: An integrative review integrative review. Journal of Perioperative Nursing 2018, 31(4): 27-35.

26. Haesler E, Rayner R, Carville K. The pan pacific clinical practice guideline for the prevention and management of pressure injury. Wound Practice \& Research: Journal of the Australian Wound Management Association 2012; 20:6-20.

27. EPUAP. European Pressure Ulcer Advisory Panel, National Pressure Ulcer Advisory Panel. Available from:http://www.epuap.org/wp-content/uploads/2016/10/ qrg prevention in turkish.pdf, 2009.

28. Osuala E. Innovation in prevention and treatment of pressure ulcer: Nursing implication. Trop Journal of Medical Resources 2014; 17:61.

29. Özel B. Bası yarası olan hastaların yönetimi. Arșiv Kaynak Tarama Dergisi 2014; 23:492-505.

30. Ayello EA, Braden B. How and why to do pressure ulcer risk assessment. Advances in Skin \& Wound Care 2002; 15:125-31.

31. Tel H, Özden D, Çetin P. Yatağa bağımlı hastalarda basınç yarası gelişme riski ve hemșirelerin bu hastalara uyguladıkları önleyici bakım. Hemșirelikte Araștırma Geliștirme Dergisi 2006; 1:35-45.

32. Jankowski MI, Nadzam MD. Identifying gaps, barriers, and solutions in implementing pressure ulcer prevention programs, The joint Commission. Journal on Quality and Patient Safety 2011, 37:154-160.

33. Çelik S, Dirimeşe E, Taşdemir N, Aşık Ş, Demircan S, Eyican S. Hemşirelerin bas yarasını önleme ve yönetme bilgisi. Bakırköy Tıp Dergisi 2017; 13:133-39.

34. Pieper B, Mott M. Nurses' knowledge of pressure ulcer prevention, staging, and description. Advances in Wound Care: The Journal for Prevention and Healing $1995 ; 8: 34-8$

35. Lawrence P, Fulbrook P, Miles S. A survey of Australian nurses' knowledge of pressure injury/pressure ulcer management. J Wound Ostomy Continence Nurs. $2015 ; 42: 450-60$.

36. Gul A, Andsoy II, Ozkaya, B, Zeydan, A. A descriptive, cross-sectional survey of turkish nurses' knowledge of pressure ulcer risk, prevention, and staging. Ostomy Wound Manage 2017; 63:40-6.

37. Fulbrook P, Lawrence P, Miles S. Australian nurses' knowledge of pressure injury prevention and management: A cross-sectional survey. Journal of Wound Ostomy and Continence Nursing 2019; 46:106-12.

38. Nuru N, Zewdu F, Amsalu S, Mehretie Y. Knowledge and practice of nurses towards prevention of pressure ulcer and associated factors in Gondar University Hospital, BMC Nursing 2015;14:1-8.

39. Chen HL, Chen XY, Wu J. The Incidence of Pressure Ulcers in Surgical Patients of the Last 5 Years: A Systematic Review. Wounds 2012; 24(9):14-19.

40. Qaddumi J, Khawaldeh A. Pressure ulcer prevention knowledge among Jordanian nurses: a cross- sectional study. BMC Nurs 2014; 13:6.

41. Awali ZM, Nagshabandi EA, Elgmail A. The Effect of Implementing Pressure U1cer Prevention Educational Protocol on Nurses' Knowledge, Attitude and Practices Nursing and Primary Care 2018; 2:1-7.

42. Rocha LES, Ruas E de FG, Santos JAD, Lima CA, Carneiro JA, Costa FM. Prevention of pressure ulcers: Evaluation of nursing professionals knowledge. Cogitare Enfermagem 2015; 20:596-604.

43. Etafa W, Argaw Z, Gemechu E, Melese B. Nurses' attitude and perceived barriers to pressure ulcer prevention. BMC Nursing 2018; 17:14-22.

44. Taha, AS. Nurses knowledge and practices related to pressure ulcer at intensive care unit. Journal of International Academic Research for Multidisciplinary 2014;2:247-62.

45. Ebi WE, Menji ZA, Hunde BM. Nurses' knowledge and Perceived Barriers About Pressure Ulcer Prevention for Admitted Patients in Public Hospitals in Addis Ababa, Ethiopia. American Journal of Internal Medicine 2017; 5:1-6.
46. Claudia G, Diane M, Daphney SG, Danièle D. Prevention and treatment of pressure ulcers in a university hospital centre: A correlational study examining nurses' knowledge and best practice. International Journal of Nursing Practise 2010; 16:183-87.

47. Ilesanmi RE, Ofi BA, Adejumo PO. Nurses' knowledge of pressure ulcer prevention in ogun state, Nigeria: results of a pilot survey. Ostomy Wound Manage 2012; 58:24-32.

48. Ünver S, Fındık ÜY, Özkan ZK, Sürücü C. Attitudes of surgical nurses towards pressure ulcer prevention. Journal of Tissue Viability 2017; 26:277-81.

49. Aydin AK, Karadag A. Assessment of nurses' knowledge and practice in prevention and management of deep tissue injury and stage I pressure ulcer. Journal of Wound Ostomy Continence Nursing 2010; 37:487-94.

50. Aydın AK, Karadağ A, Gül Ş, Avşar P, Baykara ZG. Nurses' knowledge and practices related to pressure injury: A cross-sectional Study. Journal of Wound, Ostomy and Continence Nursing 2019; 46:117-23.

51. Iranmanesh S, Tafti AA, Rafiei H, Dehghan M, Razban F. Orthopaedic nurses' knowledge about pressure ulcers in Iran: a cross-sectional study. J Wound Care $2013 ; 22: 138-40$

52. Chianca TCM, Rezende JFP, Borges EL, Nogueira VL, Caliri MHL. Pressure ulcer knowledge among nurses in a Brazilian university hospital. Ostomy Wound Manage 2010; 56:58-64.

53. Samuriwo R, Downding D. Nurses' pressure ulcer related judgments and decisions in clinical practice: A systematic review. International Journal of Nursing Studies 2014; 51:1667:85. 